\title{
Presenting features and molecular genetics of primary hyperparathyroidism in the paediatric population
}

\author{
Yasmine El Allali ${ }^{1}$, Coralie Hermetet ${ }^{2}$, Justine Bacchetta ${ }^{3}$, Cyril Amouroux ${ }^{4}$, Anya Rothenbuhler ${ }^{5}$, \\ Valérie Porquet-Bordes ${ }^{6}$, Marie-Alexandrine Champigny ${ }^{7}$, Sabine Baron ${ }^{8}$, Pascal Barat ${ }^{9}$, \\ Hélène Bony-Trifunovic ${ }^{10}$, Karine Bourdet ${ }^{11}$, Kanetee Busiah ${ }^{12}$, Maryse Cartigny-Maciejewski ${ }^{13}$, \\ Florence Compain ${ }^{14}$, Régis Coutant ${ }^{15}$, Jessica Amsellem-Jager ${ }^{15}$, Marc De Kerdanet ${ }^{16}$, Nathalie Magontier ${ }^{17}$, \\ Brigitte Mignot ${ }^{18}$, Odile Richard ${ }^{19}$, Sylvie Rossignol ${ }^{20}$, Sylvie Soskin ${ }^{20}$, Aurélie Berot ${ }^{21}$, \\ Catherine Naud-Saudreau ${ }^{22}$, Jean-Pierre Salles ${ }^{6}$, Agnès Linglart ${ }^{5}$, Thomas Edouard ${ }^{6}$ and Anne Lienhardt-Roussie7
}

${ }^{1}$ Paediatric Unit, Blois General Hospital, Blois, France, ${ }^{2}$ Epidemiology and Public Health Unit, Tours University Hospital, Tours, Centre, France, ${ }^{3}$ Service de Néphrologie, Rhumatologie et Dermatologie Pédiatriques, Centre de Référence des Maladies Rares du Calcium et

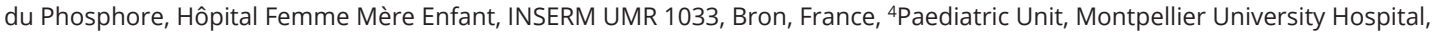
Montpellier, Languedoc-Roussillon, France, ${ }^{5}$ Assistance Publique-Hôpitaux de Paris (AP-HP), Hôpital Bicêtre Paris Saclay, Endocrinology and Diabetology for Children, Reference Centre for Rare Diseases of Calcium and Phosphate Metabolism, OSCAR Network, ERN BOND, Le Kremlin-Bicêtre, Toulouse, France, ${ }^{6}$ Endocrine, Bone Diseases, and Genetics Unit, Reference Centre for Rare Diseases of Calcium and Phosphate Metabolism, OSCAR Network, ERN BOND, Children's Hospital, Toulouse University Hospital, INSERM UMR 1043/CNRS 5828, Paul Sabatier University, Toulouse, France, ${ }^{7}$ Paediatric Unit, Limoges University Hospital, Limoges, France, ${ }^{8}$ Paediatric Unit, Nantes University Hospital, Nantes, Pays de la Loire, France, ${ }^{9}$ Paediatric Unit, Bordeaux University Hospital, Bordeaux, Aquitaine, France, ${ }^{10}$ Paediatric Unit, Amiens University Hospital, Amiens, Picardie, France, ${ }^{11}$ Paediatric Unit, Brest University Hospital, Brest, Bretagne, France, ${ }^{12}$ Endocrinology and Diabetology for Children, Necker University Hospital, AP-HP, Paris, Île-deFrance, France, ${ }^{13}$ Paediatric Endocrinology Unit, Lille University Hospital, Lille, Hauts-de-France, France, ${ }^{14}$ Paediatric Unit, Poitiers University Hospital, Poitiers, France, ${ }^{15}$ Paediatric Endocrinology Department, Angers University Hospital, Angers, Pays de la Loire, France, ${ }^{16}$ Paediatric Unit, Rennes University Hospital, Rennes, Bretagne, France, ${ }^{17}$ Paediatric Unit, Tours University Hospital, Tours, Centre, France, ${ }^{18}$ Paediatric Unit, Besançon University Hospital, Besançon, France, ${ }^{19}$ Paediatric Unit, Saint-Etienne University Hospital, Saint-Etienne, Rhône-Alpes, France,

${ }^{20}$ Paediatric Unit, Strasbourg University Hospital, Strasbourg, Alsace, France, ${ }^{21}$ Paediatric Unit, Reims University Hospital, Reims, Champagne-Ardenne, France, and 22Paediatric Unit, Lorient General Hospital, Lorient, France

Correspondence

should be addressed to A Lienhardt-Roussie Email

anne.lienhardt@chu-limoges. $\mathrm{fr}$

\footnotetext{
Abstract

Aim: To describe the presenting features and molecular genetics of primary hyperparathyroidism (PHPT) in the paediatric population.

Methods: Retrospective study of 63 children diagnosed with primary PHPT from 1998 to 2018.

Results: Compared to older children, infants were often asymptomatic ( $54 \%$ vs $15 \%, P=0.002)$ with a milder form of PHPT. When symptomatic, children and adolescents mostly presented with non-specific complaints such as asthenia, depression, weight loss, vomiting or abdominal pain. A genetic cause of PHPT was identified in about half of this cohort (52\%). The infancy period was almost exclusively associated with mutation in genes involved in the calciumsensing receptor (CaSR) signalling pathway (i.e. CaSR and AP2S1 genes, 'CaSR group'; 94\% of infants with mutations) whereas childhood and adolescence were associated with mutation in genes involved in parathyroid cell proliferation (i.e. MEN1, CDC73, CDKN1B and RET genes, 'cell proliferation group'; 69\% of children and adolescents with mutations). Although serum calcium levels did not differ between the two groups $(P=0.785)$, serum PTH levels and the urinary calcium/creatinine ratio were significantly higher in 'cell proliferation group' patients compared to those in the 'CaSR group' ( $P=0.001$ and 0.028 , respectively).
}

Published by Bioscientifica Ltd 
Conclusion: Although far less common than in adults, PHPT can develop in children and is associated with significant morbidity. Consequently, this diagnosis should be considered in children with non-specific complaints and lead to monitoring of mineral homeostasis parameters. A genetic cause of PHPT can be identified in about half of these patients.

\section{Introduction}

Primary hyperparathyroidism (PHPT) is characterised by autonomous parathyroid hormone (PTH) hypersecretion by the parathyroid glands, regardless of serum calcium levels. This can lead to hypercalcaemia which, if severe, can trigger numerous clinical signs and complications (1). PHPT is very common in adults (incidence of 1 in 1000, and the third most common endocrine disorder after diabetes mellitus and hyperthyroidism) and often asymptomatic (2). In contrast, it is very rare in children with an estimated incidence of 2-5 in 100 000 , and often associated with end-organ damage such as nephrocalcinosis, nephrolithiasis and/or skeletal complications $(3,4,5,6,7,8,9,10,11,12,13,14)$. Disease severity in children has been linked to delayed diagnosis secondary to failure to check calcium and PTH levels when investigating children with non-specific complaints such as asthenia, depression, weight loss, vomiting or abdominal pain. Asymptomatic hypercalcaemia may also be discovered incidentally in some cases.

Although most cases of PHPT have been considered sporadic due to single parathyroid adenoma, the genetic bases underlying PHPT have been highlighted over the past 30 years with the focus on two key molecular mechanisms $(1,15,16)$. First, PHPT can be caused by mutations in genes involved in the proliferation of parathyroid cells, especially in the multiple endocrine neoplasia (MEN) scenario. The mutation of these genes, including MEN1, CDKN1B, CDKN2B, CDKN2C, $C D C 73, R E T$ and GCM2 genes, is responsible for single or multiple adenomas associated with increased PTH production. Secondly, PHPT can be triggered by abnormal control of PTH secretion from the parathyroid glands in response to ionised calcium concentrations. Indeed, PTH secretion is tightly controlled by concentrations of extracellular ionised calcium through interaction with calcium-sensing receptors (CaSR) located on the plasma membrane of parathyroid cells. Mutations in CaSR-encoding genes or components of the downstream signalling pathway (GNA11 and AP2S1) lead to PTH secretion regardless of serum calcium levels. Inactivation of CaSR gene mutations has been identified as a cause of severe neonatal hyperparathyroidism (NSHPT) or benign familial hypocalciuric hypercalcemia (FHH) in older children. More recently, mutations in the SLC12A1 gene (responsible for antenatal Bartter syndrome) have been reported in children with neonatal-onset PHPT (17). However, the underlying cause of PHPT in this syndrome remains unclear.

Most of the literature on paediatric PHPT has been limited to case reports and small series with only six studies enrolling more than 20 children $(3,7,11,12,13$, 18). Moreover, most of the published studies reported only on children and adolescents, excluding neonatal PHPT and FHH. Finally, to our knowledge, only a few studies have reported genetic testing in children with PHPT (13). In the present study, we aimed to describe the presenting features and the molecular genetics in a large French national multicentre cohort of children with PHPT from birth to adulthood.

\section{Patients and methods}

\section{Patient population}

The current retrospective study included children (from 0 to 18 years of age) diagnosed with primary PHPT and followed up in the French Reference and Competence Centres for Rare Diseases in Calcium and Phosphate Metabolism, over the past 20 years (1998-2018). The diagnosis of PHPT was established by a combination of hypercalcaemia, hypophosphatemia and elevated or nonsuppressed serum PTH levels. A cohort of 84 patients was identified including 63 index cases and 21 patients diagnosed by family genetic screening. Only index cases have been included in the analysis. 
The development of Reference and Competence Centres for Rare Diseases in Calcium and Phosphate Metabolism since 2005 in France has been linked to the creation of patient cohorts included in a national database for rare diseases. Consequently, before 2005, patients were identified through keywords in hospital databases and after 2005, from reference and competence centre databases.

Our study was approved by the Limoges Institutional Research Ethics Committee (No. 236-2018-02). Written informed consent was obtained from the child's parent(s) or legal guardian(s). Patient data were anonymised and encrypted prior to analysis.

\section{Data collection}

Data were retrospectively extracted from medical records. We collated patients' family and personal history, age at presentation, gender, clinical presentation and preoperative biochemical and hormonal findings. Preoperative localisation of the parathyroid glands including neck ultrasonography, ${ }^{99 m}$ Technetium(Tc)SestaMIBI scintigraphy, MRI and PET were reviewed. Surgical findings, histopathology, postoperative course and final outcomes were documented.

Mineral homeostasis parameters including serum total calcium, phosphate, magnesium, alkaline phosphatase (ALP), parathyroid hormone (PTH), 25-hydroxy vitamin D (25-OHD) levels and urinary calcium/creatinine ratio determined by local laboratories were recorded. Normative values for serum phosphate levels and urinary calcium/creatinine ratio according to age were determined according to published reference data (19). Vitamin D insufficiency and deficiency were defined as serum 25-OHD below $20 \mathrm{ng} / \mathrm{mL}$ (50 nmol/L) and $10 \mathrm{ng} /$ $\mathrm{mL}$ (25 nmol/L), respectively (20). Serum PTH levels were expressed as the percentage of normal maximal values for each laboratory.

All patients underwent genetic testing. However, the molecular analyses were performed in various genetic units and the number of genes studied differed between centres. Informed consent for genetic analyses was obtained from legal guardians as part of the standard management procedure.

\section{Statistical analysis}

Normally distributed data are expressed as the mean value (s.D.), data not normally distributed are expressed as median (range) and dichotomous variables as a percentage.
Patients were stratified into different subgroups according to age and genotype for the statistical analysis. Independent t-tests and ANOVA were used to compare normally distributed continuous variables and the Mann-Whitney U test to evaluate skewed variables. The $\chi^{2}$ test was used to analyse categorical data. Associations were determined using the Pearson or Spearman rank correlation. All tests were two-tailed and $P<0.05$ was deemed significant. Analyses were performed with SPSS Statistics software, version 23.

\section{Results}

Sixty-three children with PHPT (28 males, 35 females; male/female ratio: 0.8) were enrolled in this study. Regarding age at diagnosis, there were two incidence peaks, one during infancy (before 2 years of age, 24 children, 38\%) and the other during childhood (by 5 years of age) and adolescence (39 children, 62\%) (Fig. 1). The main clinical and biological characteristics of these two age groups are summarised in Table 1. A genetic cause of PHPT was identified in about half of these patients (33 out of 63 patients, 52\%) (Fig. 2).

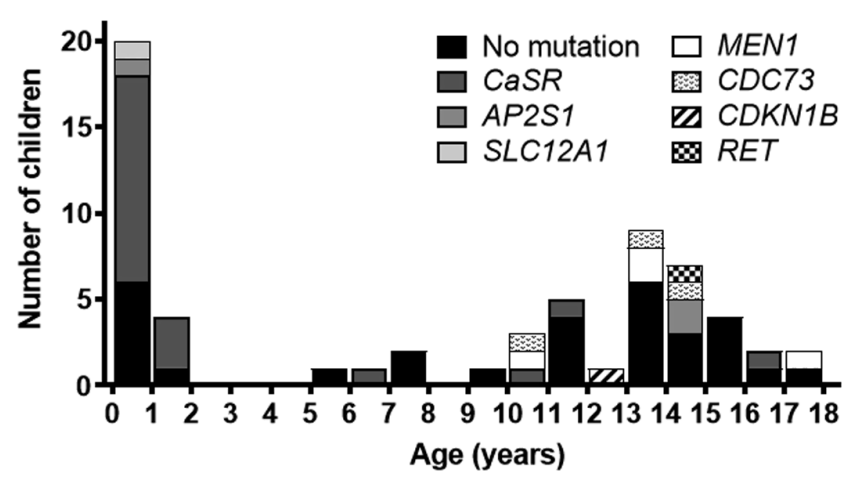

\section{Figure 1}

Age at diagnosis of children with PHPT according to genotype. The age at diagnosis was recorded in two prevalent periods, one during infancy (before 2 years of age: 24 children (38\%)) and the other during childhood (up to 5 years of age) and adolescence (39 children (62\%)). Both periods were associated with two different groups of genes, infancy being almost exclusively associated with the mutation in genes involved in the CaSR signalling pathway (CaSR and AP2S1 genes: 94\% of infants with mutations) and childhood and adolescence with the mutation in genes linked to abnormal parathyroid glands (MEN1, CDC73, CDKN1B and RET genes, $69 \%$ of children with mutations). 
Table 1 Age-related clinical, biological and genetic characteristics of 63 paediatric patients with primary hyperparathyroidism.

Data are expressed as $n(\%)$ or as median (min-max).

\begin{tabular}{|c|c|c|c|c|c|c|c|}
\hline & \multicolumn{2}{|c|}{ Whole cohort } & \multicolumn{2}{|c|}{ Infant group } & \multicolumn{2}{|c|}{ Child and adolescent group } & \multirow[b]{2}{*}{$P$ value $^{1}$} \\
\hline & $n$ & Value & $n$ & Value & $n$ & Value & \\
\hline Number of patients & 63 & & 24 & & 39 & & \\
\hline Gender (male/female, ratio) & 63 & $28 / 35(0.8)$ & 24 & $11 / 13(0.8)$ & 39 & $17 / 22(0.8)$ & 0.378 \\
\hline Age at diagnosis (years) & 63 & $10.4(0.0-17.5)$ & 24 & $1.5(0.1-23.6)$ & 39 & $13.2(5.0-17.5)$ & 0.0001 \\
\hline Asymptomatic disease & 63 & $19(30 \%)$ & 24 & $13(54 \%)$ & 39 & $6(15 \%)$ & 0.002 \\
\hline Serum calcium (mmol/L) & 63 & $2.98(2.40-4.70)$ & 24 & $2.97(2.70-4.60)$ & 39 & $2.99(2.66-4.70)$ & 0.588 \\
\hline Low serum phosphate ${ }^{2}$ & 60 & $46(77 \%)$ & 22 & $17(77 \%)$ & 38 & $29(76 \%)$ & 0.0001 \\
\hline PTH (\% normal maximal value) & 63 & $63(17-4221)$ & 24 & $71(17-303)$ & 39 & $201(30-4221)$ & 0.001 \\
\hline 25-OHD (ng/mL) & 53 & $24(7-84)$ & 22 & $33(18-84)$ & 31 & $21(7-82)$ & 0.001 \\
\hline Urinary $\mathrm{Ca} / \mathrm{Cr}$ ratio $(\mathrm{mmol} / \mathrm{mmol})$ & 55 & $0.84(0.00-9.75)$ & 22 & $0.85(0.00-9.75)$ & 33 & $0.84(0.00-4.47)$ & 0.918 \\
\hline Inherited form & 63 & $31(49 \%)$ & 24 & $15(63 \%)$ & 39 & $16(41 \%)$ & 0.900 \\
\hline Genetic cause identified & 63 & $33(52 \%)$ & 24 & $17(71 \%)$ & 39 & $16(41 \%)$ & 0.705 \\
\hline
\end{tabular}

${ }^{1} P$ values represent the significance of the difference between the 'infant group' and the 'child and adolescent group'; 'Low serum phosphate was defined as serum phosphate $<2.5$ th percentile according to age from reference (19).

$\mathrm{Ca}$, calcium; $\mathrm{Cr}$, creatinine.

\section{Characteristics of infants with PHPT}

In this group including 24 patients (11 males, 13 females) under 2 years of age, the median age at referral was 1.5 months (range: 3 days to 2 years of age). About half of the patients (13 out of 24 patients, 54\%) were asymptomatic and hypercalcaemia was discovered incidentally in a blood test performed for another reason (i.e. prematurity, small for gestational age). In the 11 symptomatic patients, clinical signs at referral were failure to thrive (4 patients), digestive signs (4 patients), bone deformity ( 2 patients), neurological signs (3 patients) or renal abnormality (dilated urinary tract; 1 patient).

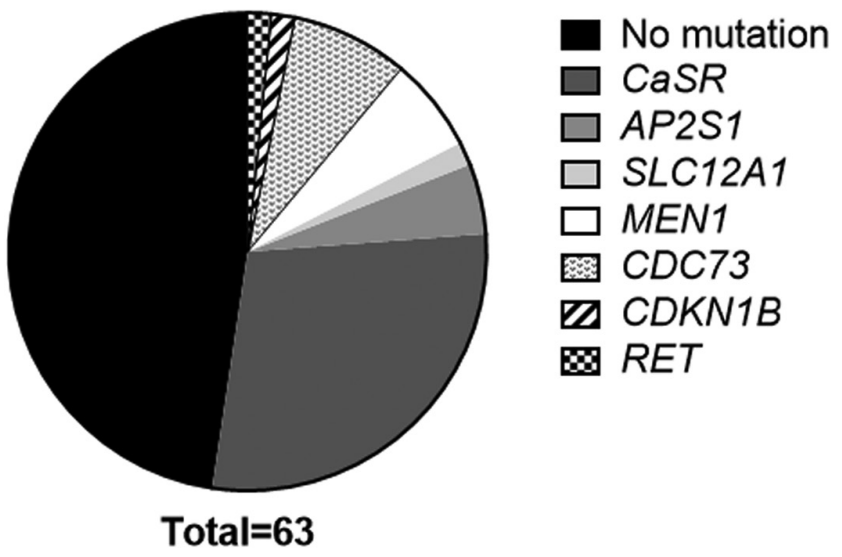

Figure 2

Distribution of gene variants in children with PHPT. A genetic cause of PHPT was identified in about half of patients (33 out of 63 patients $(52 \%))$. Most patients carried a heterozygous mutation in the CaSR gene.
As expected, total serum calcium levels were always increased with median calcaemia of $2.97 \mathrm{mmol} / \mathrm{L}$ (range: $2.70-4.60 \mathrm{mmol} / \mathrm{L}$ ) associated with elevated or nonsuppressed serum PTH levels in all cases. Serum phosphate levels for 22 children were low $(<2.5$ th percentile according to age) in 17 children (77\%) and normal in 5 (23\%). Most patients (19 out of 22 patients with available data, $86 \%$ ) had low or normal values in their urinary calcium/creatinine ratio that were not adjusted in line with hypercalcaemia.

Of the 21 patients with available renal ultrasound scans, four presented renal complications of hypercalcaemia (nephrocalcinosis in 3 and kidney stone in one). Unfortunately, except for two patients with bone deformity, skeletal X-rays were not systematically performed - hence PHPT-related bone abnormalities could not be investigated in this infant group.

Cervical ultrasonography was performed to explore parathyroid glands in 6 out of 24 patients (25\%). Parathyroid hyperplasia was detected in only one patient with SLC12A1 gene mutation.

In this infant group, treatment was mainly medical based on hyperhydration (12 patients, 50\%) combined with diuretics (7 patients, 29\%), bisphosphonates (6 patients, 25\%) or cinacalcet (1 patient, 4\%). Only one patient with SLC12A1 gene mutation underwent partial parathyroidectomy for parathyroid hyperplasia. Cinacalcet therapy was maintained postoperatively in this patient to control persistent hypercalcaemia.

A familial form of PHPT was present in 15 out of the 24 infants (63\%). Genetic diagnosis was conducted in 17 out of the 24 infants $(71 \%)$, most of whom (15 
patients, 88\%) presented with CaSR gene mutation (in the heterozygous state in all but one patient); the other two infants displayed AP2S1 and SLC12A1 gene mutations. These muations were inherited from one of the parents in 10 out of 17 cases (59\%). The clinical and biological data collated for these mutated patients did not differ statistically from patients with no genetic diagnosis.

\section{Characteristics of children and adolescents with PHPT}

This group included 39 children ( 22 females, 17 males) with a median age at referral of 13.2 years (range: $5.0-17.5$ years of age). In contrast to the infant group, most of the patients (33 out of 39 patients, $87 \%$ ) were symptomatic at the time of diagnosis. The main clinical features are summarised in Table 2. No patient presented with acute pancreatitis.

Hypercalcaemia was present in all but one patient with a median calcium level of $2.99 \mathrm{mmol} / \mathrm{L}$ (range: $2.40-4.70$ $\mathrm{mmol} / \mathrm{L}$ ). Serum phosphate levels available for 38 children were low ( $<2.5$ th percentile according to age) in 29 children (76\%) and normal in 9 (24\%). Two- thirds of patients (22 out of 35 patients with available data, 63\%) presented a high urinary calcium/creatinine ratio that was adjusted in line with hypercalcaemia. The median serum level of 25-OHD recorded in 31 children was $21 \mathrm{ng} / \mathrm{mL}$ (range: $7-82 \mathrm{ng} / \mathrm{mL})$ with vitamin D deficiency $(<10 \mathrm{ng} / \mathrm{mL})$ in 4 children (10\%) and vitamin D insufficiency (10-20 ng/ $\mathrm{mL})$ in 11 (28\%). Nephrocalcinosis was found in 5 out of 36 children with available renal ultrasound scans (14\%) Normal renal function was documented in all of these cases. Osseous manifestation of PHPT (i.e. osteopenia, subperiosteal bone resorption, cortical dualisation and metaphyseal irregularities) were detected in 9 out of 22 children with available skeletal X-rays (41\%).

Table 2 Clinical characteristics at the referral of 39 children and adolescents with primary hyperparathyroidism.

\begin{tabular}{l} 
Characteristics \\
\hline Asymptomatic \\
General signs (asthenia, weight loss) \\
Digestive signs (vomiting, abdominal pain) \\
Neuropsychological signs (lethargy, depression, \\
$\quad$ emotional behaviour disorder) \\
Polyuria \\
Short stature \\
Bone pain \\
Bone fracture \\
Kidney stones \\
Nephrocalcinosis
\end{tabular}

Values, $\boldsymbol{n}(\%)$ $6(15)$

$12(31)$

$17(43)$

$3(8)$

$7(18)$

$4(10)$

$3(8)$

$3(8)$

$10(26)$

5 (13)

${ }^{1} T$ hree patients displayed wrist, vertebral and clavicular fractures.
All patients underwent parathyroid gland localisation studies. Parathyroid glands were investigated by neck ultrasonography in 31 out of the 39 children (79\%), ${ }^{99 \mathrm{~m}}$ Tc-SestaMIBI scintigraphy in 34 cases (87\%), MRI in 4 (10\%) and PET in 10 cases (26\%). A combination of these different techniques led to the diagnosis of adenoma in half of the patients (20 out of $39,51 \%$ ). The sensitivity and specificity in localising parathyroid adenomas were $89 \%$ and $58 \%$ for ultrasonography and $95 \%$ and $50 \%$ for ${ }^{99 m}$ Tc-SestaMIBI scintigraphy, respectively.

Preoperative medical treatment in the 39 children and adolescents consisted of hyperhydration (30 patients, 77\%) combined with diuretics (8 patients, $21 \%)$, bisphosphonates (17 patients, $44 \%$ ) or cinacalcet (6 patients, 15\%). Twenty-three out of 39 patients (59\%) underwent a surgical procedure that revealed single parathyroid adenomas in 18 patients and multiple adenomas in two patients. Two patients required a second procedure shortly after the first for ectopic parathyroid glands located in the mediastinum. Both patients presented with permanent hypoparathyroidism postoperatively. Apart from these patients, shortterm post-surgical complications comprised transient hypocalcaemia in nine patients and transient vocal cord paralysis in one patient. The median follow-up period was 1.8 years ranging from 1 month to 10 years. Only one patient with RET gene mutation experienced a relapse during follow-up, 3 years after the initial surgery.

A familial form of PHPT was diagnosed in 16 out of 39 children and adolescents (41\%). When adenoma was confirmed, it was generally sporadic ( 14 out of 20 patients with adenoma, 70\%). Genetic diagnosis was performed in 16 out of 39 children (41\%). Most of the mutations (11 out of $16,69 \%$ ) were detected in genes linked to abnormal parathyroid cell proliferation (MEN1 $(n=4), C D C 73(n=5)$, CDKN1B $(n=1)$ and RET $(n=1)$ genes). Family genetic investigations revealed one affected parent in half of these cases (6 affected parents, 55\%). Five children (31\%) presented gene mutation affecting the CaSR signalling pathway (CaSR $(n=3)$ and AP2S1 $(n=2)$ genes), which was inherited in all cases.

\section{Characteristics of patients with PHPT according to genotype}

Two groups of patients were identified according to the statistical analysis genotype: patients with gene mutation involving the CaSR signalling pathway (CaSR and AP2S1 genes, 'CaSR group') and patients with gene mutations linked to abnormal parathyroid cell proliferation (MEN1, 
CDC73, CDKN1B and RET genes, 'cell proliferation group'). Clinical and biological data according to genotype is summarised in Table 3.

As described previously, there was an important correlation between age at diagnosis and genotype. Indeed, the infancy period was almost exclusively associated with 'CaSR group' gene mutation (94\% of infants with mutations) whereas childhood and adolescence were associated with the mutation of 'cell proliferation group' genes (69\% of children with mutations). Most patients in the 'cell proliferation group' (8 out of 11 patients, 73\%) were symptomatic compared to only half of patients (11 out of 21 children, 52\%) in the 'CaSR group' but this was not significant. Although serum calcium levels did not differ between the two groups $(P=0.785)$, as expected, PTH levels and urinary calcium/creatinine ratio were significantly higher in 'cell proliferation group' patients compared to those in the 'CaSR group' $(P=0.001$ and 0.028 , respectively).

\section{Discussion}

The present study reports on the clinical and biological characteristics coupled with the molecular genetics of a large paediatric PHPT cohort. This report is original on several counts. First, in contrast to previous studies in which infants are usually considered separately, children of all ages, from birth to adulthood, were included, thus portraying a wide range of paediatric presentations and causes of PHPT. Secondly, this report provides data on molecular genetics that are usually lacking in other published studies. Indeed, although sometimes incomplete, genetic testing was performed in all of our patients, leading to the identification of a genetic mutation in about half of the cohort (33 of 63 patients, $52 \%$ ). In the only study reporting molecular genetic anomalies in a large paediatric PHPT population, genetic testing was only performed in 24 of 59 patients (40\%) and revealed mutation in only 8 cases (33\%) (13).

In contrast to adults, in whom PHPT is very common, with an estimated incidence of $1 / 1000$, PHPT is rare in children but the precise incidence rate remains unknown. In a previous French series including 55 children (11 infants and 44 children and adolescents) with PHPT diagnosed over a 20-year period (from 1984 to 2004), the incidence was estimated at 1/ 200000 - 300000 live births (12). Our series, which is not exhaustive, did not confirm the precise incidence of PHPT in children. However, it is interesting to note that, over the same 20-year period (from 1998 to 2018), a similar number of children and adolescents was diagnosed with PHPT compared to those reported in the Mallet et al. study (39 vs 44 children and adolescents). In contrast, the number of infants diagnosed with PHPT doubled ( 24 vs 11 infants) in comparison to the same study. This could be attributed to the more frequent monitoring of mineral homeostasis in neonates and infants.

Regarding age at diagnosis of PHPT, two incidence peaks were documented - one during infancy (38\%) and the other during childhood and adolescence (62\%) - corresponding to two distinct presentations and molecular mechanisms. Thus, infants were often asymptomatic with a milder form of PHPT compared to older children. Moreover, the infancy period was almost exclusively associated with the

Table 3 Clinical and biological characteristics according to the genotype of the 32 paediatric patients with the genetic diagnosis. Values are expressed as $n(\%)$ or as median (min-max).

\begin{tabular}{|c|c|c|c|c|c|}
\hline & \multicolumn{2}{|c|}{ CaSR group (CaSR and AP2S1 genes) } & \multicolumn{2}{|c|}{$\begin{array}{c}\text { Cell proliferation group (MEN1, } \\
C D C 73, C D K N 1 B \text { and } R E T \text { genes) }\end{array}$} & \multirow[b]{2}{*}{ P value $^{1}$} \\
\hline & $n$ & Value & $n$ & Value & \\
\hline Number of patients & 21 & & 11 & & \\
\hline Gender (male/female) & 21 & $9 / 12$ & 11 & $3 / 8$ & 0.117 \\
\hline Age at diagnosis (years) & 21 & $0.5(0.0-14.7)$ & 11 & $13.1(9.8-17.5)$ & 0.0001 \\
\hline Asymptomatic disease & 21 & $10(48 \%)$ & 11 & $3(27 \%)$ & 0.223 \\
\hline Serum calcium (mmol/L) & 21 & $2.94(2.70-4.60)$ & 11 & $3.05(2.66-4.70)$ & 0.785 \\
\hline Low serum phosphate ${ }^{2}$ & 20 & $16(80 \%)$ & 11 & $8(73 \%)$ & 0.002 \\
\hline PTH (\% normal maximal value) & 21 & $70(17-295)$ & 11 & $308(108-4221)$ & 0.0001 \\
\hline 25-OHD (ng/mL) & 20 & $29(8-84)$ & 8 & $25(9-82)$ & 0.685 \\
\hline Urinary $\mathrm{Ca} / \mathrm{Cr}$ ratio $(\mathrm{mmol} / \mathrm{mmol})$ & 19 & $0.59(0.04-9.75)$ & 9 & $1.06(0.50-3.97)$ & 0.028 \\
\hline Inherited form & 21 & $14(67 \%)$ & 11 & $6(55 \%)$ & 0.077 \\
\hline $\begin{array}{l}n \text { represents number of patients with a } \\
{ }^{1} P \text { values represent the significance of th } \\
\text { serum phosphate }<2.5 \text { th percentile accc } \\
\text { Ca, calcium; } C r \text {, creatinine. }\end{array}$ & & $\begin{array}{l}\text { ‘CaSR group } \\
\text { ce (19). }\end{array}$ & & $;{ }^{2}$ Low seru & defi \\
\hline
\end{tabular}


mutation of genes involved in the CaSR signalling pathway (94\% of infants with mutations) whereas childhood and adolescence were associated with the mutation of genes involved in parathyroid cell proliferation (69\% of children and adolescents with mutations).

About half of the infants to the present study were asymptomatic, which is in direct contrast to other studies reporting mainly severe NSHPT $(12,21)$. This high rate of asymptomatic patients is probably related to the more frequent monitoring of calcaemia in premature infants or those with a low birth-weight for gestational age. In symptomatic infants, the most frequent referral sign was failure to thrive and digestive signs, which are consistent with other studies. Interestingly, only one of the 24 infants underwent partial parathyroidectomy compared to the vast majority (around two-thirds) in earlier studies $(6,12)$. This is, of course, due not only to the less severe form of PHPT, but also to the more frequent use of medical treatment such as bisphosphonates and, more recently, calcimimetics (cinacalcet). In NSHPT, it is assumed that uncontrolled PTH secretion leads to increased bone resorption. Consequently, the use of bisphosphonates that inhibit osteoclastic bone resorption seems logical. However, it has been reported that this treatment has variable efficacy in new-borns, and may sometimes be accompanied by a rebound increase in serum PTH and hypercalcaemia $(22,23,24,25,26)$. A better understanding of the molecular basis of NSHPT helps to propose specific treatment. Calcimimetics that interact with the CaSR transmembrane domain, making the receptor more sensitive to extracellular ionized calcium, specifically address the problem of abnormal CaSR function. Several cases of NSHPT successfully treated with cinacalcet have been reported $(22,24,26,27,28,29)$.

Regarding the children and adolescents with PHPT, the results of our study are comparable to those of previous reports and confirm that the presentation of PHPT in this age group differs significantly from the typical adult form. As reported in other studies $(3,4,9,10$, 12), our work highlighted a modest female predominance (male/female ratio of 0.8). However, equal distribution and the slight preponderance of males have also been reported $(6,30,31)$. These inter-study discrepancies in gender rates may be due to small sample sizes. This ambiguity is not evident for adult patients in whom PHPT is four times more common in women than men (2). In contrast, there is no ambiguity in disease severity, which is more marked in children compared to adults. Indeed, the high incidence of symptomatic patients in our series $(80 \%)$ is similar to other paediatric reports (3,
$9,12,30)$ and in contrast to adult patients with only $20 \%$ (to 50\%) of primary PHPT patients being symptomatic at diagnosis. It has been suggested that this discrepancy between children and adult PHPT patients may be due to the lack of routine serum calcium checks in children presenting non-specific complaints. Apart from the latter (i.e. asthenia, weight loss and digestive signs), kidney stones were the most common presenting symptom as previously reported. It is also important to emphasise the frequency of neuropsychological signs in children (such as lethargy, depression, emotional behaviour disorder) which may be indicative of the disease. The frequency of bone involvement (40\%) is lower than in previous reports (ranging from 70 to $100 \%)(4,12,13,32$ ), and is probably due to the lack of systematic skeletal investigation in this study. Thus, in the absence of severe bone damage (e.g. fracture), the true prevalence of asymptomatic bone lesions (such as excessive subperiosteal bone resorption or reduced cortical bone mass) is likely to have been underestimated in our analysis. Half of the patients presented adenoma that was sporadic in $70 \%$ of the cases. A genetic cause was established in $40 \%$ of patients, thus contrasting with adult PHPT patients in whom underlying genetic causes are usually absent.

In this study, hypercalcaemia resolved successfully in $90 \%$ of children following surgery compared to $94 \%$ in previous studies $(3,13)$. The absence of any permanent postoperative complications and recurrence in our paediatric population suggests that, despite being generally symptomatic at diagnosis, paediatric patients can be treated successfully through surgery, just like adults.

There are some limitations in the present study. First, due to the study's retrospective and multicentre design, some data were missing or incomplete. For instance, biochemical parameters such as ionised calcium and serum magnesium levels were often missing and, as discussed previously, bone involvement was not systematically evaluated because of the lack of routine bone investigation. Although genetic testing was performed in all patients, the number of genes analysed differed between centres, notably in the case of more recently identified genes (such as CDKN1B, CDC73, AP2S1, SLC12A1 genes). Thus there would be an unavoidable selection bias in evaluating the mutation rate of the entire PHPT paediatric population.

\section{Conclusion}

Although far less common than in adults, PHPT can develop in children and is associated with significant 
morbidity. Consequently, this diagnosis should be considered in children with non-specific complaints and lead to monitoring of mineral homeostasis parameters. A genetic cause of PHPT can be identified in about half of these patients and can be used in effective case management (e.g. specific treatment by calcimimetics in patients with abnormal CaSR function).

\section{Declaration of interest}

The authors declare that there is no conflict of interest that could be perceived as prejudicing the impartiality of this study.

\section{Funding}

This research did not receive any specific grant from any funding agency in the public, commercial or not-for-profit sector.

\section{Author contribution statement}

T E and A L-R contributed equally to this work.

\section{References}

1 Bilezikian JP, Bandeira L, Khan A \& Cusano NE. Hyperparathyroidism. Lancet 2018391 168-178. (https://doi. org/10.1016/S0140-6736(17)31430-7)

2 Fraser WD. Hyperparathyroidism. Lancet 2009374 145-158. (https:// doi.org/10.1016/S0140-6736(09)60507-9)

3 Kollars J Zarroug AE Heerden Jv, Lteif A, Stavlo P, Suarez L, Moir C, Ishitani $\mathrm{M} \&$ Rodeberg D. Primary hyperparathyroidism in pediatric patients. Pediatrics 2005115 974-980.

4 Bhadada SK, Bhansali A, Dutta P, Behera A, Chanukya GV \& Mittal BR. Characteristics of primary hyperparathyroidism in adolescents. Journal of Pediatric Endocrinology and Metabolism 200821 1147-1153. (https://doi.org/10.1515/jpem.2008.21.12.1147)

5 George J, Acharya SV, Bandgar TR, Menon PS \& Shah NS. Primary hyperparathyroidism in children and adolescents. Indian Journal of Pediatrics 201077 175-178. (https://doi.org/10.1007/s12098-0090289-5)

6 Girard RM, Belanger A \& Hazel B. Primary hyperparathyroidism in children. Canadian Journal of Surgery 198225 11-13, 32.

7 Harman CR, van Heerden JA, Farley DR, Grant CS, Thompson GB \& Curlee K. Sporadic primary hyperparathyroidism in young patients: a separate disease entity? Archives of Surgery 1999134 651-655; discussion 655-656. (https://doi.org/10.1001/archsurg.134.6.651)

$8 \mathrm{Hu}$ Y, Chen X, Chen X, Zhang S, Jiang T, Chang J \& Gao Y. Bone loss prevention of bisphosphonates in patients with inflammatory bowel disease: a systematic review and meta-analysis. Canadian Journal of Gastroenterology and Hepatology 20172017 2736547. (https://doi. org/10.1155/2017/2736547)

9 Lawson ML, Miller SF, Ellis G, Filler RM \& Kooh SW. Primary hyperparathyroidism in a paediatric hospital. QJM 199689 921-932. (https://doi.org/10.1093/qjmed/89.12.921)

10 Loh KC, Duh QY, Shoback D, Gee L, Siperstein A \& Clark OH. Clinical profile of primary hyperparathyroidism in adolescents and young adults. Clinical Endocrinology 199848 435-443. (https://doi. org/10.1046/j.1365-2265.1998.00329.x)

11 Lou I, Schneider DF, Sippel RS, Chen H \& Elfenbein DM. The changing pattern of diagnosing primary hyperparathyroidism in young patients. American Journal of Surgery 2017213 146-150. (https://doi.org/10.1016/j.amjsurg.2016.03.019)

12 Mallet E \& Working Group on Calcium Metabolism. Primary hyperparathyroidism in neonates and childhood. The French experience (1984-2004). Hormone Research 200869 180-188. (https://doi.org/10.1159/000112592)

13 Wang W, Kong J, Nie M, Jiang Y, Li M, Xia W, Meng X, Xing X \& Wang O. Primary hyperparathyroidism in Chinese children and adolescents: a single-centre experience at Peking Union Medical College Hospital. Clinical Endocrinology 201787 865-873. (https:// doi.org/10.1111/cen.13453)

14 Mukherjee S, Bhadada SK, Arya AK, Singh P, Sood A, Dahiya D, Ram S, Saikia UN \& Behera A. Primary hyperparathyroidism in the young: comparison with adult primary hyperparathyroidism. Endocrine Practice 201824 1051-1056. (https://doi.org/10.4158/ EP-2018-0268)

15 Roizen J \& Levine MA. Primary hyperparathyroidism in children and adolescents. Journal of the Chinese Medical Association 201275 425-434. (https://doi.org/10.1016/j.jcma.2012.06.012)

16 Cetani F, Saponaro F, Borsari S \& Marcocci C. Familial and hereditary forms of primary hyperparathyroidism. Frontiers of Hormone Research 201951 40-51. (https://doi.org/10.1159/000491037)

17 Li D, Tian L, Hou C, Kim CE, Hakonarson H \& Levine MA. Association of mutations in SLC12A1 encoding the NKCC2 cotransporter with neonatal primary hyperparathyroidism. Journal of Clinical Endocrinology and Metabolism 2016101 2196-2200. (https:// doi.org/10.1210/jc.2016-1211)

18 Saponaro F, Marcocci C, Cacciatore F, Miccoli M, Pardi E, Borsari S, Materazzi G, Miccoli P \& Cetani F. Clinical profile of juvenile primary hyperparathyroidism: a prospective study. Endocrine 201859 344-352. (https://doi.org/10.1007/s12020-017-1318-1)

19 Ardeshirpour L, Cole DE \& Carpenter TO. Evaluation of bone and mineral disorders. Pediatric Endocrinology Reviews 20075 (Supplement 1) 584-598.

20 Munns CF, Shaw N, Kiely M, Specker BL, Thacher TD, Ozono K, Michigami T, Tiosano D, Mughal MZ, Makitie O et al. Global Consensus recommendations on prevention and management of nutritional rickets. Journal of Clinical Endocrinology and Metabolism 2016101 394-415. (https://doi.org/10.1210/jc.2015-2175)

21 Norwood S \& Andrassy RJ. Primary hyperparathyroidism in children: a review. Military Medicine 1983148 812-814. (https://doi. org/10.1093/milmed/148.10.812)

22 Fisher MM, Cabrera SM \& Imel EA. Successful treatment of neonatal severe hyperparathyroidism with Cinacalcet in two patients. Endocrinology, Diabetes and Metabolism Case Reports 20152015 150040. (https://doi.org/10.1530/EDM-15-0040)

23 Murphy H, Patrick J, Baez-Irizarry E, Lacassie Y, Gomez R, Vargas A, Barkemeyer B, Kanotra S \& Zambrano RM. Neonatal severe hyperparathyroidism caused by homozygous mutation in CASR: a rare cause of life-threatening hypercalcemia. European Journal of Medical Genetics 201659 227-231 (https://doi.org/10.1016/j. ejmg.2016.02.001)

24 Reh CM, Hendy GN, Cole DE \& Jeandron DD. Neonatal hyperparathyroidism with a heterozygous calcium-sensing receptor (CASR) R185Q mutation: clinical benefit from Cinacalcet. Journal of Clinical Endocrinology and Metabolism 201196 E707-E712. (https:// doi.org/10.1210/jc.2010-1306)

25 Savas-Erdeve S, Sagsak E, Keskin M, Magdelaine C, LienhardtRoussie A, Kurnaz E, Cetinkaya S \& Aycan Z. Treatment experience and long-term follow-up data in two severe neonatal hyperparathyroidism cases. Journal of Pediatric Endocrinology and Metabolism 201629 1103-1110. (https://doi.org/10.1515/jpem-2015-0261)

26 Sun X, Huang L, Wu J, Tao Y \& Yang F. Novel homozygous inactivating mutation of the calcium-sensing receptor gene in neonatal severe hyperparathyroidism responding to Cinacalcet 
therapy: a case report and literature review. Medicine 201897 e13128. (https://doi.org/10.1097/MD.0000000000013128)

27 Forman TE, Niemi AK, Prahalad P, Shi RZ \& Nally LM.

Cinacalcet therapy in an infant with an R185Q calcium-sensing receptor mutation causing hyperparathyroidism: a case report and review of the literature. Journal of Pediatric Endocrinology and Metabolism 201932 305-310. (https://doi.org/10.1515/jpem2018-0307)

28 Gannon AW, Monk HM \& Levine MA. Cinacalcet monotherapy in neonatal severe hyperparathyroidism: a case study and review. Journal of Clinical Endocrinology and Metabolism 201499 7-11. (https://doi.org/10.1210/jc.2013-2834)

29 Wilhelm-Bals A, Parvex P, Magdelaine C \& Girardin E. Successful use of bisphosphonate and calcimimetic in neonatal severe primary hyperparathyroidism. Pediatrics 2012129 e812-e816. (https://doi. org/10.1542/peds.2011-0128)

30 Hsu SC \& Levine MA. Primary hyperparathyroidism in children and adolescents: the Johns Hopkins Children's Center experience 1984-2001. Journal of Bone and Mineral Research 200217 (Supplement 2) N44-N50.

31 Bjernulf A, Hall K, Sjogren L \& Werner I. Primary hyperparathyroidism in children. Brief review of the literature and a case report. Acta Paediatrica Scandinavica 197059 249-258. (https:// doi.org/10.1111/j.1651-2227.1970.tb09000.x)

32 Li CC, Yang C, Wang S, Zhang J, Kong XR \& Ouyang J. A 10-year retrospective study of primary hyperparathyroidism in children. Experimental and Clinical Endocrinology and Diabetes 2012120 229-233. (https://doi.org/10.1055/s-0032-1301895)

Received 30 September 2020

Accepted 28 November 2020 